\title{
Forest Fire Prevention Data: A Change in Perspectives
}

by

Paul M. Woodard ${ }^{1}$ and Joe Niederleitner ${ }^{2}$

\begin{abstract}
Forest fire prevention data from ten different forest protection agencies in Canada were analyzed and evaluated. Data currently being collected fail to provide the information required for effective fire prevention programs. Information on the unsafe acts and conditions at the time and place of burning is required if protection staffs are to develop more specific education, engineering and enforcement programs to reduce wildfire occurrence. The sampling intensity for collecting fire prevention data does not seem to be justified in light of the minor variation in ignition causes between years.
\end{abstract}

\section{Résumé}

Des données de prévention des feux de forêt fournies par dix sociétés de protection du Canada ont été analysées. Les données recueillies en ce moment font défauts concernant les informations pertinentes à des programmes efficaces de prévention. De l'information sur les risques et les conditions entourant le moment et le site du feu est nécessaire si les responsables de la protection veulent développer des programmes plus précis d'éducation, d'ingénierie et d'action pour réduire les feux. En présence des faibles variations d'année en année des causes de démarrage des feux, il n'y a pas lieu de considérer un échantillonnage intense des données de prévention.

\section{Introduction}

Forest fires are a significant management problem in Canada. Forest fire statistics published by Ramsey and Higgins (1981) suggest Canada experiences almost 9000 fires per year which burn over an average of 1.1 million hectares of forest land annually. They report the average value lost each year exceeds $\$ 33$ million and this figure does not include suppression costs. Perhaps even more significant is the fact that $65 \%$ of all fires in Canada or $15 \%$ (164 $498 \mathrm{ha}$ ) of the total forest area burned annually are due to man-caused ignitions.

The number and size of these fires can be reduced if forest managers have access to factual data on the acts or conditions which result in wildland fires. If explicit, this information will enable foresters to initiate engineering, education and enforcement programs that will reduce the number of preventable forest fires. ${ }^{3}$ In our opinion, current fire prevention data do not provide this information. Therefore, in this manuscript we evaluate the type and quality of the fire prevention data being

\footnotetext{
Associate Professor, Forest Fire Science/Management. Department of Forest Science, University of Alberta, Edmonton, Alberta T6G $2 \mathrm{H} 1$

2Planning Section Head, Forest Protection Branch, Alberta Forest Service, P.O. Box 7040, Postal Station " M", Edmonton, Alberta T5E 5S9.

3Preventable forest fire is defined for this paper as a fire which results due to a lack of knowledge, carelessness, or malicious behavior on the part of a forest
} user or because of improper management of the fuel complex. collected by ten fire management agencies in Canada, question the data collection intensity and recommend a change in perspectives. We believe a change in perspectives is required if the type of information required for specific and efficient fire prevention programs is to be collected.

\section{Current Practices}

All forest protection agencies sampled record and analyze data pertaining to the cause of individual forest fires. The amount and type of data collected varies between agencies. Most agencies attempt to identify what is commonly called the "class of people" or "activity" responsible for the ignition (Table 1) and the "specific" ignition cause (Table 2). In general, this information is used to identify the target population or activity which represents the greatest risk while the "specific" cause will eventually become the target of a fire prevention message or program (Brown and Davis 1973). In addition, these data are often classified by "general" causes of ignition (Table 3). This last classification enables agencies to group fires for the purpose of comparing "general" fire cause data within and between protection units across Canada (Ramsey and Higgins 1981). Generally, fire cause data are number coded for easy storage, manipulation and retrieval by a computer (Simard et al. 1973). This number coded material provides the data base for the fire prevention programs in Canada. 
Table 1. A compendium of responsible groups or activities as recognized by the 10 agencies studied. The list of groups has been stratified by general cause without regard for how the proponent agency categorized them.

\begin{tabular}{lllllllllllll}
\hline & & & D & & & & & & & \\
& A & & I & & & & & & & S \\
Responsible & I & & A & M & & & O & P & Q & a \\
Group & t & B & N & a & N & N & n & E & u & s \\
Reur & a & C & D & n & B & S & t & I & e & k
\end{tabular}

\section{Recreational}

Berry pickers

Bikers

Boaters (Canoeist)

Campers

Excursionists

Fisherman

Guide party

Hiker

Highway traveller

Hunter

Other

Picnicker

Private cottager

Railroad passenger

Recreation opns/

const ${ }^{1}$ employees

Tourist

Youth groups

\section{Resident}

Children

Commercial fisherman

Commercial resort

$$
\text { owner }
$$

Farmer

General public

Indian (on reserve)

Local permanent

worker/resident

Owner

Rural resident

Seasonal worker/ resident

Settler

Urban resident

Forest industry

Blueberry culture

crews

Federal gov't employees

Fire protection personnel

Forest service employees

Hazard reduction crews

Land surveyors

Logging crews

Lumber mill

employees

Miscellaneous employees

Operations employees

Other governmental employees

Peat harvest crews

Private forestry crews

Reforestation

employees

Silvicultural crews

Timber cruisers

\begin{tabular}{lllllllllllll} 
& & & & D & & & & & & & & \\
& A & & I & & & & & & & S \\
Responsible & I & & A & M & & & & O & P & Q & a \\
Group & t & B & N & a & N & N & n & E & u & s \\
\hline & a & C & D & n & B & S & t & I & e & k \\
\hline
\end{tabular}

\section{Incendiary}

General

Pyromaniac

Setting fire for a joke

Setting fire for

vengeance

Setting fire for profit

\section{Unknown}

Miscellaneous known

Non-applicable

Other

Police officer on duty

Transients

\section{Other industry}

Construction crew

Hydro opns/const. ${ }^{\prime}$ employees

Industrial site clearing crews

Military

Mining opns./Const.' employees

Municipality employees

Other industrial employees

Other (specify)

Pipeline workers

Power commission employees

Prospectors

Public projects

Right-of-way construction crews

Right-of-way maintenance crews

Road workers

Telephone company employees

Trappers

Truckers

Unknown (government)

Water travellers (commercial)

Workers

Railroad

Railroad operating crews

Railroad work crews

-Operation/construction = opns./const. 


\begin{tabular}{llllllllllll} 
& & & & D & & & & & & & \\
& A & & I & & & & & & & S \\
Specific & I & & A & M & & & & O & P & Q & a \\
Cause & t & B & N & a & N & N & n & E & u & S \\
& a & C & D & n & B & S & t & I & e & k \\
\hline
\end{tabular}

Aircraft

Blasting operations/

Explosives

Bonfire

Breakshoe fragments

Brush burning,

domestic

Brush burning.

industrial

Burning blueberry plains

Burning buildings

Burning debris

Burning right-of-way

Burning trash (rubbish)

not in a regular

dump area

Burning vehicle

Campfire

Camp stove, (or)

lamp exploding

Children with matches

Chimney spark

Cigar

Cigarette

Derailment

Dumped live coals or ashes

Exhaust spark no arrester

Faulty spark arrester

Fireworks

Friction: log lines blocks/skidding

Fusee

Garbage dump fire

Glass

Hangover logging slash

Hangover millsite/ landing

Hangover (other)

Hazard reduction

Helicopter

Hot ashes

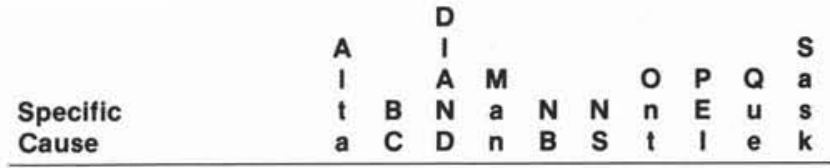

Incendiary

Land clearing

Landing debris fire

Lightning

Locomotive spark or ash

Logging machine

Match

Mechanical equipment

Mill burner

Millsite debris

Miscellaneous known

Oil and gas well

Other (specify)

Pipe heel

Power line

Powersaw exhaust

Powersaw other causes

Prescribed burning

$R / R$ tie and/or bush burning

Range burning/Grass burning

Refuse burning, domestic

Refuse burning industrial

Skidder

Slash burn

Slash fire with permit

Slash fire without permit

Slasher

Smoker

Smudge

Sparks Other

Spontaneous combustion

Tractor (light)

Unknown

Unspecified smoking material

Warning fire

Welding

\footnotetext{
BC: British Columbia

DIAND: Department of Indian and Northern Affairs

NB New Brunswick

Sask: Saskatchewan

Man: Manitoba

PEl: Prince Edward Island

Ont: Ontario

Alta: Alberta

NS: Nova Scotia

Que: Quebec
} 
Table 3. General causes of forest fires as recognized by the provincial or federal agencies listed. Note the first nine categories listed have been ratified and adopted by the Canadian Committee on Forest Fire Control.

\begin{tabular}{|c|c|c|c|c|c|c|c|c|c|c|c|}
\hline & & & & D & & & & & & & \\
\hline & & A & & I & & & & & & & $\mathbf{S}$ \\
\hline & & I & & A & M & & & 0 & P & $\mathbf{Q}$ & a \\
\hline General & . & $t$ & B & $\mathbf{N}$ & $\mathbf{a}$ & $\mathbf{N}$ & $\mathbf{N}$ & $\mathbf{n}$ & E & $\mathbf{u}$ & $\mathbf{s}$ \\
\hline Causes & & a & C & D & $\mathbf{n}$ & B & s & $t$ & I & e & $k$ \\
\hline
\end{tabular}

1 Lightning

2 Recreation

3 Resident

4 Forest Industry

5 Other-Industry

6 Railroad

7 Incendiary

8 Unknown

9 Miscellaneous

10 Settlement

11 Public Project

12 Land Clearing

14 Logging

15 Woods Operation

16 Agriculture

17 Other
13 Right-Of-Way

\section{Discussion}

Initially, it would seem that information on who starts wildfires (Table 1) and how wildfires are started (Table 2) would contribute to better fire prevention programs (Donoghue 1982a). But the data collected and analyzed, even if accurate (Chandler 1960), only show most wildfires are the result of legitimate and often necessary human activity in the forest. This information fails to explain why usually safe burning activity results in wildfires. It is not enough to know how many wildfires were caused by railroad operations or even more specifically railroad operating crews or railroad work crews (Table 1). Additionally, it is of little value to know how many fires were started by railroad passengers tossing lit cigarettes out of train windows or the number due to "hot" breakshoe fragments or even "hot" bearing boxes (Table 2). We know all of these "responsible groups" or "specific" causes are capable of initiating forest fires - but they rarely do. Therefore, it would seem more important to know why in some instances these "activities" or "specific" causes resulted in wildfires while at other times, which are the majority of cases, they did not. We as forest managers need to know what actual act or condition or combinations of the two was responsible for each wildfire (Folkman 1956). But the "specific" cause data being collected do not provide managers with the information required. From this perspective it is clear that current prevention data are manageable but not meaningful.

Prevention data should enable managers to develop specific programs of instruction, engineering or legislation to eliminate "actual" fire causes. We question the usefulness of collecting information which tells a manager how many fires in a protection area were due to, for example, "campfires" (Table 2) established by fishermen, hunters, logging crews, boaters, picnickers, or bikers (Table 1) or "power saws" (Table 2) operated by hazard reduction crews, rural residents, campers, private cottagers, or telephone company employees (Table 1) because this information fails to identify why these activities resulted in wildfires.

There are a number of reasons why campfires cause wildfires. A list of the most common reasons would show it is because they were not fully extinguished, were not attended, or were built under overhanging trees, on deep duff layers, or in dry grass. Information pertaining to hazard-risk relationships (unsafe conditions or acts) at the place where a forest fire was initiated would enable managers to develop specific programs or messages to eliminate or reduce the number of these unsafe acts or conditions which are the actual cause of campfire-related wildfires.

Power saws do not normally cause forest fires, regardless of who is operating them, but faulty spark arresters, missing muffler covers or the refueling of "hot" saws on flammable material may. Education and enforcement programs can reduce or eliminate the number of fires caused by individuals refueling "hot" power saws on flammable materials. Wildfires caused by faulty spark arresters or missing muffler covers could be significantly reduced or eliminated through enforcement or engineering programs.

Fire prevention programs are rarely specific. General awareness messages such as "Only you can prevent a forest fire" or "Be careful with fire" which are being used extensively by protection agencies are of limited value. These kinds of messages do not inform or increase an individual's awareness of what acts or conditions are unsafe. Individuals who were never taught how to prevent a forest fire or how to be careful with fire may not be able to comply - even if they wanted to. Not only are these slogans too general; but more importantly, the results of such programs are not measurable. We cannot assign a cost-benefit value to particular messages or programs even if a certain man-cause category is reduced, because we do not know which message or program, if any. was responsible. There are a number of reasons why prevention agencies have relied on general awareness campaigns. Yet, we believe it's basically because they have lacked the data required to develop more specific and innovative programs.

Fire prevention data must be more informative if the costbenefit ratio of present prevention programs is to be more accurately evaluated and if future programs are to be adequately justified. For example, almost $19 \%$ of all man-caused forest fires in Alberta during the period 1961-1979 were classified as "resident fires". These fires were thought to be due to improper procedures on the part of the landowner because that was how the coded data were interpreted. A more thorough investigation of this fire problem, now suggests some "resident fires" in this Province were due to errors made by the forest officer, who, for a variety of reasons erred by issuing the burning permit. This additional information on the actual causes of "resident"-related wildfires in Alberta has enabled us to more effectively allocate our limited protection budget. We are no longer devoting most of our resources to developing newspaper advertising campaigns or producing elaborate prevention brochures. Instead, we are using some of these resources to re-evaluate permit issuance procedures and to better train and more efficiently locate patrolmen. But "actual cause" information has other important uses. For example, if we as forest managers knew exactly how many wildfires were due to particular types of equipment failures or faulty equipment design, then legislation requiring changes in equipment design or specifications could be justified.

\section{Recommendations}

There exists a need for more precise fire prevention data. The number and variety of wildfire causes suggest some protection officers have recognized this need. There are at least 78 responsible groups or "activity" classes (Table 1 ) and 69 "specific" cause categories (Table 2) in use in Canada. Certainly not all of these cause categories or classes are unique. Some are a reflection of specific fuel or activity prob- 
lems associated with a particular protection area (i.e. "blueberry culture crew" fires in New Brunswick and Quebec) but most are used in more than one protection area suggesting a need for more precise data. Nevertheless, a thoughtful review of all cause or class categories suggests there is no difference in the kind of information being collected. Further, none of these categories really explain why a wildfire resulted. To that end, we recommend protection agencies begin to record the "actual" cause of each man-related wildfire. Examples of some "actual" man-related fire causes are listed in Table 4.

Initially, this "actual" cause data will not be easy to collect, or to code, store and analyze by machine. Data collection will not be easy because the information required is more precise than that which is being collected. Highly trained investigators will be needed at times because the "actual" cause may not be readily apparent or known. For example, using the present classification system, it would be easy to classify the "specific" cause of an escaped land clearing fire as "brush burning". It would be far more difficult to determine the "actual" cause if it was due to unforecasted high winds or to the fact the fire was unattended at the time of escape. But that is the kind of information forest managers need regardless of the difficulty and costs involved in obtaining it.

\section{Table 4. Examples of actual forest fire causes which would enable forest managers to develop better prevention programs. \\ 1. Unforcasted change in weather (wind, temperature, $\mathrm{RH}$ ). \\ 2. Fire unattended. \\ 3. Control lines constructed to standard but inadequate because radiation heat transfer was responsible for the fire crossing the fire guarded perimeter. \\ 4. Burning permit should not have been issued (reason*) DC, DMC or BUI were to high \\ - fuels not properly arranged \\ "forcasted weather dangerous \\ *inadequate control lines \\ -suppression equipment required not available \\ "forest officer failed to inspect site}

5. Campfire improperly constructed because

6. Hazard too high for associated risk because

7. Careless behavior (ex)

8. Unavoidable (ex)

9. Unsafe procedures (ex)

10. Equipment failure (ex)

11. Fire not extinguished

Initially, it may be difficult to machine code, store and analyze this new data because (1) not all "actual" cause categories are known at this time, and (2) the number of "actual" causes will depend on the level of accuracy desired. However. only the eight or ten most important causes need be identified. The other less frequent causes can be lumped under a collective title such as "Others". We believe by initially recording all facts related to each individual man-caused fire, a definitive and manageable number of "actual" cause categories will emerge. This is how the cause categories in use today were determined (Donoghue 1982a). These new categories then can be number coded for easy manipulation.

Protection agencies will not have to make extensive changes in established prevention data collection proce- dures. Much of the data collected now are useful; although we cannot justify a need for collecting the "specific" cause information shown in Table 2. Most forest protection agencies in Canada will not even have to change their fire report forms, because from our survey half of them already have a "Remarks Section" on their form. This section could be used for recording this additional information. However, we recommend that agencies consider adopting, if required, an additional fire investigation form, which could be completed for certain man-caused fire problems. If properly designed, this form will provide trained investigators with the space and management with the flexibility necessary to insure a thorough investigation is performed and the necessary information is collected.

In our opinion, fire prevention data are not extremely variable and there seems to be little need to collect this information for every wildfire. Forest managers know and have known at least since 1905 what kinds of activities cause wildfires (Brown and Davis 1973, Donoghue 1982b). Therefore, forest protection agencies should only have to collect prevention data every five to seven years unless the effects of a new prevention program are to be evaluated. It does not seem very likely the reasons for man-caused wildfires will change significantly over such a short time period. Periodic surveys should provide agencies with enough data to evaluate the effectiveness of their fire prevention efforts and to make necessary adjustments. A fire investigation report form could also reduce the amount of time and energy required to collect fire cause data (Donoghue 1982b) because this information would not be collected for every fire as is occurring now. Also, the data collected would be more precise due to the kind of information which could be required in completing the new form (Table 4). More importantly, this new form could be used as a sampling tool and the intensity of sampling could be regulated. Only cause data from randomly selected fires within a "sample" year or all fires within specific test years really need to be sampled. This document could provide the control necessary to insure a statistically adequate number of man-caused wildfires were sampled.

It is interesting to note, sub-sampling techniques common to other aspects of forestry are not used for collecting fireprevention related data. Statistical sub-sampling procedures can and should be applied to this management problem. This is particularly true if agencies have a data base which is representative of their historical fire occurrence. Subsampling could significantly reduce the amount of time required to fill out fire report forms without reducing the level of accuracy.

\section{Conclusion}

The goal of management is to understand, predict and control or influence outcomes. The amount and type of information recorded and analyzed greatly influences the effectiveness of the resulting management plans or strategies. It is a well known fact that individuals engaged in almost any activity which involves a heat source capable of producing a fire can cause a wildfire. But usually, their activity or heat source will not cause a wildfire unless specific unsafe acts or conditions are present at the time and place where burning occurs. We believe the number of man-caused fires can be significantly reduced if forest officers, trained in fire investigation procedures, collect and analyze information pertaining to unsafe acts or conditions. This information, although perhaps initially difficult and costly to obtain, will enable management to develop specific fire prevention programs which are cost effective and to better justify existing prevention activities. 
Further, fire prevention data are not so variable that agencies need to collect these data for every man-caused wildfire. Statistical procedures for sub-sampling prevention related data can and should be used. We recommend a sampling schedule which collects prevention data only every five to seven years.

\section{References}

Brown, A.A., and K.P. Davis. 1973. Forest fire: control and use. 2nd ed. McGraw-Hill Publ. Co., New York, 686 p.

Chandler, C.C. 1960. How good are statistics on fire causes. J. For 58: $515-517$
Donoghue, L.R. 1982a. Classifying wildfire causes in the USDA Forest Service: problems and alternatives. USDA For. Serv. Res. Note NC-280. 5 p.

1982b. The history and reliability of the USDA Forest Service wildfire report. USDA For. Serv. Res. Paper NC-226. $15 \mathrm{p}$.

Folkman, W.S. 1956. Forest fires as accidents: an epidemiological approach to fire prevention research. Proc. 56 th Western Forestry Conference, Dec. 1965, Vancouver, BC. p. 136-141.

Ramsey, G.S., and D.G. Higgins. 1981. Canadian forest fire statistics. Environ. Can., Canadian For. Serv. Inf. Rep. PI-X-9. 71 p.

Simard, A.J., J.D. Graham and A.S. Muir. 1973. Development of computer processing techniques for individual forest fire report data. Environ. Can., Canadian For. Serv. Inf. Rep. FF-X-40.81 p.

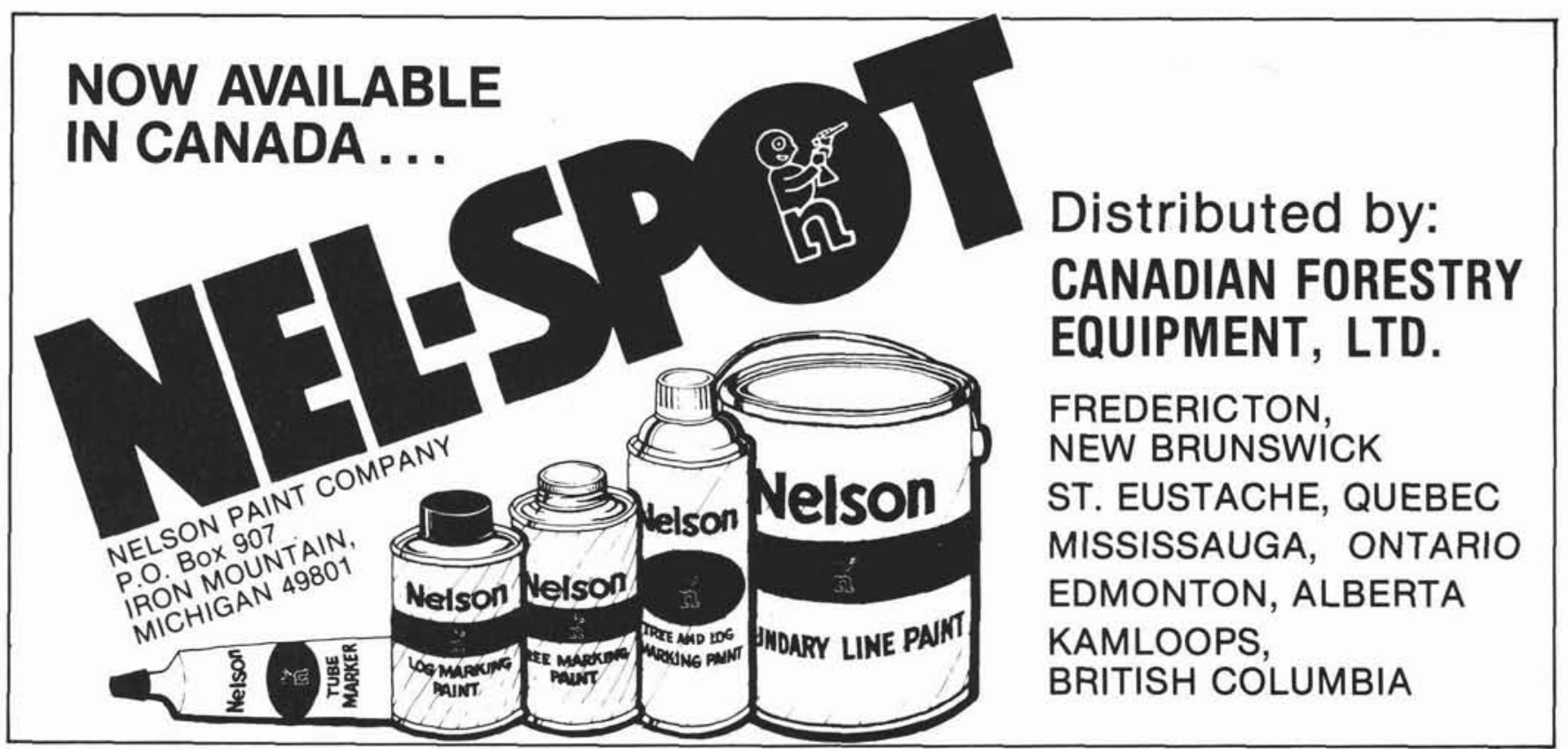

